\title{
Correction to: On-site multi-component intervention to improve productivity and reduce the economic and personal burden of neck pain in Swiss office-workers (NEXpro): protocol for a cluster-randomized controlled trial
}

Andrea M. Aegerter ${ }^{1 *}$, Manja Deforth ${ }^{1}$, Venerina Johnston ${ }^{2}$, Markus J. Ernst ${ }^{1,4}$, Thomas Volken ${ }^{1}$, Hannu Luomajoki ${ }^{1}$, Beatrice Brunner ${ }^{3}$, Julia Dratva ${ }^{1,5,6}$, Gisela Sjøgaard ${ }^{7}$, Achim Elfering ${ }^{8}$, Markus Melloh ${ }^{1,9,10}$ and on behalf of the NEXpro collaboration group

\section{Correction to: BMC Musculoskelet Disord 21, 391 (2020) https://doi.org/10.1186/s12891-020-03388-x}

Following publication of the original article [1], an error occurred during production of the paper " On-site multi-component intervention to improve productivity and reduce the economic and personal burden of neck pain in Swiss office-workers (NEXpro): protocol for a cluster-randomized controlled trial" (BMC musculoskeletal disorders 21 (1):391. doi:10.1186/s12891-020-03388$\mathrm{x})$. The correct name in the NEXpro collaboration group and the acknowledgements should be "Holger Dressel" and not "Holger Dressler".

\section{Author details}

'ZHAW School of Health Professions, Technikumstrasse 71, 8400 Winterthur, Switzerland. ${ }^{2}$ The University of Queensland, School of Health and Rehabilitation Sciences, Brisbane, Queensland, Australia. ${ }^{3}$ ZHAW School of Management and Law, Winterthur Institute of Health Economics, Gertrudstrasse 15, 8401 Winterthur, Switzerland. ${ }^{4}$ Centre of Precision Rehabilitation for Spinal Pain, School of Sport, Exercise \& Rehabilitation Sciences, University of Birmingham, Birmingham, UK. ${ }^{5}$ University of Basel,

The original article can be found online at https://doi.org/10.1186/s12891020-03388-x

* Correspondence: andrea.aegerter@zhaw.ch

'ZHAW School of Health Professions, Technikumstrasse 71, 8400 Winterthur, Switzerland

Full list of author information is available at the end of the article

Medical Faculty, Basel, Switzerland. 'University of Basel, Medical Faculty, Basel, Switzerland. ${ }^{7}$ Department of Sport Sciences and Clinical Biomechanics, University of Southern Denmark, Odense, Denmark. ${ }^{8}$ University of Bern, Institute of Psychology, Fabrikstrasse 8, 3012 Bern, Switzerland. 'The University of Western Australia, UWA Medical School, Nedlands, Western Australia, Australia. ${ }^{10}$ Curtin University, Curtin Medical School, Bentley, Western Australia, Australia.

Published online: 25 July 2020

\section{Reference}

1. Aegerter AM, Deforth M, Johnston V, et al. On-site multi-component intervention to improve productivity and reduce the economic and personal burden of neck pain in Swiss office-workers (NEXpro): protocol for a cluster-randomized controlled trial. BMC Musculoskelet Disord. 2020;21: 391 https://doi.org/10.1186/s12891-020-03388-x.

(c) The Author(s). 2020 Open Access This article is licensed under a Creative Commons Attribution 4.0 International License, which permits use, sharing, adaptation, distribution and reproduction in any medium or format, as long as you give appropriate credit to the original author(s) and the source, provide a link to the Creative Commons licence, and indicate if changes were made. The images or other third party material in this article are included in the article's Creative Commons licence, unless indicated otherwise in a credit line to the material. If material is not included in the article's Creative Commons licence and your intended use is not permitted by statutory regulation or exceeds the permitted use, you will need to obtain permission directly from the copyright holder. To view a copy of this licence, visit http://creativecommons.org/licenses/by/4.0/ The Creative Commons Public Domain Dedication waiver (http://creativecommons.org/publicdomain/zero/1.0/) applies to the data made available in this article, unless otherwise stated in a credit line to the data. 